\title{
Pengembangan Aplikasi Kehadiran Mahasiswa Berbasis Web Pada Program Studi Pendidikan Teknologi Informasi dan Komputer
}

\author{
Ferry Marlianto ${ }^{1}$, Dewi Sulistiyarini ${ }^{2}$, dan Febrianto Sabirin ${ }^{3 *}$ \\ ${ }^{123}$ Fakultas Pendidikan MIPA dan Teknologi, IKIP PGRI Pontianak \\ *e-mail: rinakasaka@gmail.com
}

\begin{abstract}
Abstrak - Proses pemerikaan kehadiran mahasiswa dan pengisian jurnal mengajar di IKIP PGRI Pontianak masih berbasis kertas yang memiliki berbagai kelemahan seperti mudah rusak, hilang, lupa dibawa atau lupa diisi. Untuk itu melalui Aplikasi Kehadiran Mahasiswa Teknologi Informasi dan Komputer (AKEMATIK), Program Studi Pendidikan Teknologi Informasi dan Komputer (P.TIK) IKIP PGRI Pontianak dapat memudahkan dosen dalam pengisian jurnal mengajar dan memantau kehadiran mahasiswa, selain itu juga dapat membantu menyusun laporan perkuliahan yang akan membantu proses evaluasi belajar mengajar di Program Studi P.TIK IKIP PGRI Pontianak. Penelitian memiliki tujuan untuk: 1) memberikan gambaran tentang proses pengembangan aplikasi; dan 2) mengetahui kelayakan aplikasi yang telah dibangun. Pengembangan aplikasi menggunakan ADDIE yang terdiri dari: analisi, desain, pengembangan, implementasi dan evaluasi. Berdasarkan model tersebut diketahui bahwa aplikasi memiliki 3 aktor yaitu admin, dosen, dan mahasiswa. validasi ahli diketahui bahwa aplikasi tergolong sangat baik. Uji alpha dilakukan kepada 15 dosen dan 30 orang mahasiswa P.TIK, berada pada kategori sangat baik.
\end{abstract}

Kata Kunci : Aplikasi Kehadiran Mahasiswa, Sistem Informasi, Website, ADDIE

\begin{abstract}
The process of checking student attendance and filling in teaching journals at IKIP PGRI Pontianak is still paper based which has various weaknesses such as being easily damaged, lost, forgetting to carry or forget to fill.Through Aplikasi Kehadiran Mahasiswa Teknologi Informasi dan Komputer (AKEMATIK), Education of Technology Information and Computer Program on IKIP PGRI Pontianak can facilitate lecturers in filling teaching journals and monitoring student attendance, while also helping to prepare lecture reports that will help evaluation of teaching and learning in the Program Studi P.TIK IKIP PGRI Pontianak. The research aims to: 1) provide an overview of the application development process; and 2) find out the feasibility of the application. Application development uses the ADDIE model which consists of 5 stages: 1) Analysis; 2) Design; 3) Development; 4) Implementation; and 5) Evaluation. Based on this model it is known that the application has 3 actors namely admin, lecturer, and student. Application testing is done by validating media experts, and alpha testing. The results of expert validation were in the excelent category. Alpha test was conducted on 15 lecturers and 30 students of P.TIK, the results were in the excellent category.
\end{abstract}

Keywords : Student Attendance Application, Information System, Website, ADDIE

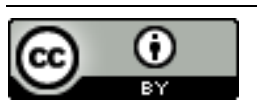

This is an open access article distributed under the Creative Commons 4.0 Attribution License

\section{Pendahuluan}

Teknologi yang berkembang pesat dalam satu dekade terakhir adalah Teknologi Informasi dan Komunikasi (TIK). Salah satu teknologi yang berkembang adalah teknologi website yang digunakan sebagai sarana untuk media promosi, pemasaran, informasi, pendidikan, dan komunikasi[1].

Dalam dunia pendidikan khususnya pendidikan tinggi, teknologi website dapat digunakan baik pada kegiatan belajar mengajar ataupun kegiatankegiatan administrasi tanpa terbatas ruang dan 
waktu[2]. Pada kegiatan belajar mengajar TIK dapat diintegrasikan dalam kegiatan perencanaan, pelaksanaan, hingga evaluasi. Sementara pada kegiatan administratif, TIK dapat digunakan untuk berbagai pelayanan dan penyajian laporan sebagai contoh pengembangan sistem informasi administrasi program studi (SIAP) [3]. Penggunaan TIK dalam pendidikan sejatinya sama seperti pada bidang lainnya yaitu guna mencapai efisiensi dan efektivitas kerja.

Salah satu penerapan TIK yang dapat diaplikasikan di IKIP PGRI Pontianak adalah aplikasi kehadiran mahasiswa yang menggunakan teknologi berbasis website. Hal ini dikarenakan, hingga saat ini di IKIP PGRI Pontianak khususnya pada Program Studi P.TIK masih menggunakan Daftar Kehadiran Mahasiswa (DHK) untuk memeriksa kehadiran mahasiswa. Penggunaan DHK sendiri memiliki berbagai kendala seperti penggunaan kertas yang mudah rusak (robek dan terkena air), hilang, hingga kemungkinan dilakukannya tindakan kecurangan seperti pemalsuan tanda tangan. Alat bantu lain yang digunakan untuk memeriksa kehadiran mahasiswa dalah jurnal perkuliahan, dimana melalui jurnal tersebut digunakan sebagai data sekunder apabila terjadi permasalahan pada DHK. Sayangnya penggunaan jurnal perkuliahan tidak terlalu reliabel, karena dosen seringkali hanya menggunakan DHK untuk mengabsen mahasiswa, sehingga jurnal perkuliahan diisi sendiri oleh mahasiswa dan hanya divalidasi oleh ketua kelas.

Pengembangan Aplikasi Kehadiran Mahasiswa Pendidikan Teknologi Informasi dan Komputer (AKEMATIK) berbasis website ini diharapkan akan mengatasi atau mengurangi permasalahan terkait pendataan kehadiran mahasiswa maupun dosen. Permasalahan yang dihadapi terkait kehadiran seperti hilang atau rusaknya DHK dapat ditiadakan, dikarenakan data akan tersimpan secara digital dan terpusat menggunakan suatu basis data sehingga data akan lebih aman. Kemungkinan kecurangan seperti fabrikasi/pemalsuan tanda tangan dosen dan titip DHK secara otomatis menjadi sangat sulit dilakukan karena yang dapat memvalidasi kehadiran hanyalah akun dosen yang bersangkutan. Dengan AKEMATIK, setiap aktor dalam sistem yang dibangun akan memperoleh laporan yang terjamin akurasinya serta tidak memerlukan waktu yang lama dalam memprosesnya [4].

Penggunaan aplikasi berbasis website juga memberikan keuntungan lebih, karena melalui aplikasi berbasis website, orang tua mahasiswa juga dapat memantau kehadiran anaknya yang berkuliah di IKIP PGRI Pontianak. AKEMATIK akan membantu orang tua untuk mendapatkan informasi terkait kehadiran anaknya[5]. Bagi orang tua mahasiswa, tentunya perlu mendapatkan informasi terkait kehadiran anaknya yang berkuliah di IKIP PGRI Pontianak, terlebih sebagian besar mahasiswa yang berkuliah di IKIP PGRI Pontianak berasal dari berbagai kabupaten/kota di Kalimantan Barat atau diluar Kalimantan Barat. Penelitian yang dilakukan Irawan dan Noor menunjukkan bahwa sistem absensi dapat dengan mudah digunakan oleh mahasiswa dan dosen, dapat memantau, serta mengontrol proses absensi mahasiswa melalui sistem tersebut [6]. Lebih lanjut, sistem informasi absensi mahasiswa akan membantu program studi, dosen, dan mahasiswa dalam merekapitulasi kehadiran mahasiswa secara berkala[7].

\section{Kehadiran Mahasiswa}

Kehadiran mahasiswa merupakan salah satu penilaian utama dalam proses pembelajaran. Menurut PERMENDIKNAS Nomor 44 Tahun 2015 bahwa setiap semester terdiri dari 16 minggu pertemuan termasuk didalamnya ujian tengah semster dan ujian akhir semester[8]. Selain itu, berdasarkan Standar Penjaminan Mutu Internal (SPMI) di IKIP PGRI Pontianak menyebutkan bahwa kehadiran mahasiswa menjadi syarat untuk dapat mengikuti ujian akhir semester. Jumlah minimal kehadiran yaitu $75 \%$ dari jumlah pertemuan yang dilaksanakan dalam satu semester. Jumlah kehadiran dosen juga diatur berdasarkan jumlah sks yang diajarkan. Menurut Penelitian Amelia dan Susi, kehadiran mahasiswa nilai akhir mahasiswa ditentukan berdasarkan kehadiran mahasiswa lebih dari 70\% [9]. Berdasarkan hal tersebut dapat diketahui bahwa kehadiran mahasiswa dapat menjadi factor utama untuk mendapatkan nilai akhir yang memuaskan.

\section{Sistem Informasi}

Sistem informasi adalah kumpulan komponen yang saling terpadu dalam menghasilkan informasi yang akurat, dan tepat guna[10]. Sistem informasi dapat pula diartikan sebagai sistem kerja yang dikhususkan untuk memproses informasi, yaitu memperoleh, mengirimkan, menyimpan, memanipulasi, dan menampilkan informasi[11].

Sistem informasi dapat diidentifikasi sebagai sistem yang mengkombinasikan hardware, software, prosedur, pengguna dan basis data[10]. Sistem informasi merupakan keseluruhan aspek pengembangan, penyebaran, implementasi, penggunaan, hingga dampak dari sistem tersebut 
dalam suatu organisasi atau masyarakat[13].

\section{Internet dan Website}

Internet merupakan jaringan komunikasi yang menghubungkan miliaran komputer di seluruh dunia dalam satu jaringan besar [14]. Setiap komputer yang terhubung pada internet memiliki alamat yang unik atau alamat yang berbeda antara satu komputer dengan komputer lainnya. Awalnya internet merupakan hasil riset dari pemerintahan amerika serikat, namun saat ini setiap orang dapat terhubung dengan internet menggunakan protocol TCP/IP (Transmission Control Protocol/Internet Protocol).

World Wide Web atau lebih familiar dengan sebutan Website merupakan bagian dari internet. Website sendiri merupakan kumpulan dokumen yang diakses melaui jaringan internet[15]. Seiring perkembangan teknologi media yang ditampilkan dalam website tidak hanya berupa teks, tetapi dapat berupa gambar, suara, atau video. Menurut Connoly dan Hoar elemen-elemen utama dari website adalah: Unified Resource Locator (URL), Hypertext Transfer Protocol (HTTP), Hypertext Markup Languange, Browser, dan web server[15].

Website sendiri dapat dibedakan menjadi website statis dan website dinamis. Website Dinamis memiliki karakteristik dimana informasi didalamnya dapat diubah sesuai dengan permintaan dari pengguna. Sementara Website Statis dapat diartikan sebagai halaman web yang informasi didalamnya tidak mengalami perubahan kecuali diubah langsung oleh pemilik website. Umumnya website statis hanya menggunakan HTML dan Cascading Style Sheet, sedangkan website dinamis selain komponen-komponen yang ada pada website statis dilengkapi pula bahasa pemrograman dan basis data.

\section{MetodA}

Penelitian yang dilakukan untuk mengembangkan aplikasi kehadiran mahasiswa menggunakan metode Research \& Development. Model pengembangan yang digunakan yaitu ADDIE (Analysis, Design, Development, Implementation, Evaluate).

Aplikasi kehadiran siswa dikembangkan berbasis web dan terhubung ke internet. Aplikasi ini menggunakan PHP, HTML, CSS Bootsrap, JavaScript, dan MySQL. Dalam database ini memerlukan beberapa syarat yang diperlukan oleh admin dalam memasukkan mata kuliah dan mahasiswa dalam mendaftar mata kuliah.

Aplikasi ini dapat menghasilkan laporan mengenai kehadiran mahasiswa, kehadiran dosen, jurnal perkuliahan dosen, daftar mata kuliah dan dosen pengampu. Dalam aplikasi ini pengguna dapat berupa pimpinan program studi, dosen, staf, dan mahasiswa.

Kelebihan dari aplikasi ini berbasis internet dan bisa digunakan di berbagai aplikasi dan sistem operasi, dapat diakses dimanapun berada tetapi harus tetap terhubung dengan internet, memudahkan penggunaan dalam melakukan kehadiran mata kuliah, useless paper, dan dapat memberitahukan pengguna dengan menggunakan e-mail terkait perkuliahan. Aplikasi ini juga bersifat responsive web, yaitu bisa digunakan dalam berbagai perangkat, dekstop, tablet dan smartphone. Selama perangkat tersebut terhubung ke dalam internet.

Untuk mendapatkan hasil layak atau tidak terhadap pengembangan aplikasi kehadiran mahasiswa, dilakukan validasi dan uji coba produk. Pengumpulan data dilakukan dengan menggunakan angket yang diberikan kepada ahli media, dosen, dan mahasiswa. Hasil yang diperoleh akan dihitung dan lihat untuk dilakukan perbaikan guna menyempurnakan aplikasi tersebut.

\section{HASIL DAN PEMBAHASAN}

AKEMATIK berbasis website merupakan sebuah sistem informasi yang dibangun untuk mempermudah Program Studi terutama dosen dan mahasiswa dilingkungan IKIP PGRI Pontianak dalam melakukan absensi kehadiran mahasiswa. Selain itu, aplikasi juga memudah Program Studi dalam memantau pelaksaaan proses pembelajaran, aktivitas dosen dan mahasiswa, serta pelaporan yang terstruktur, akuntabel, dan trasnparan.

AKEMATIK memiliki tiga aktor, yaitu admin, dosen, dan mahasiswa. Setiap aktor memiliki hak akses yang berbeda. Admin merupakan aktor yang dapat menambah, menghapus, dan mengubah data master yaitu data dosen, admin, mata kuliah, tahun akademik, kurikulum, dan jadwal kuliah. Mahasiswa merupakan aktor yang dapat melakukan proses absensi kehadiran dalam aplikasi. Sementara Dosen merupakan aktor yang dapat memverifikasi proses kehadiran yang dilakukan oleh Mahasiswa. 


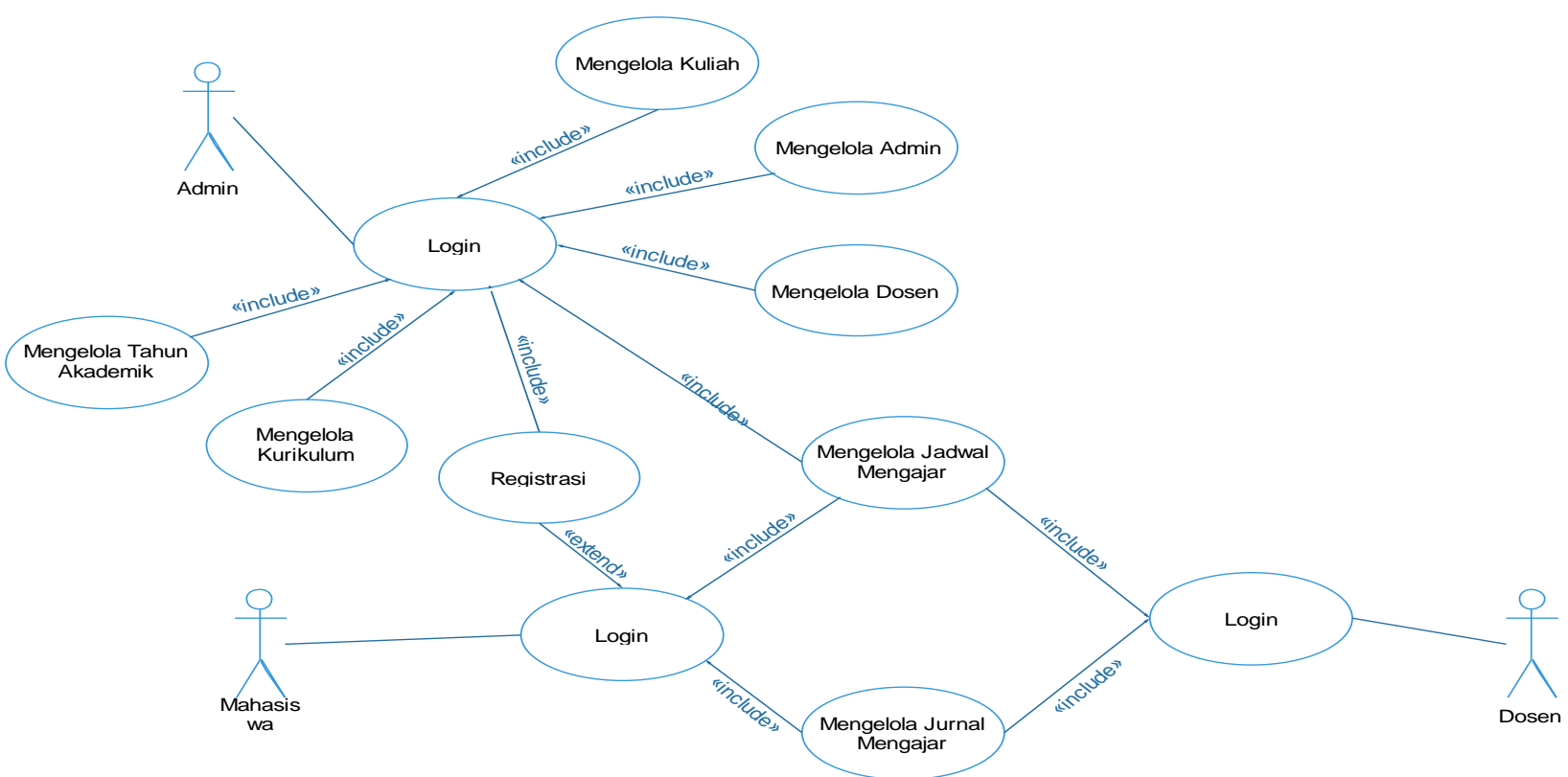

Gambar 1. Use Case AKEMATIK IKIP PGRI Pontianak

Untuk menjalankan AKEMATIK, admin perlu mempersiapkan data master untuk aplikasi AKEMATIK. Admin pertama-tama perlu mempersiapkan akun untuk dosen-dosen pada Program Studi P.TIK IKIP PGRI Pontianak. Akun dosen terdiri dari Nomor Induk Dosen Nasional (NIDN), Nomor Pokok Pegawai (NPP), nama dosen, pendidikan. Data dosen ini akan digunakan untuk direlasikan dengan data perkuliahan, selain itu data dosen juga digunakan oleh dosen untuk masuk ke dalam AKEMATIK. Data dosen hanya dapat dibuat oleh Admin untuk menjaga keamanan sistem, sehingga tidak sembarang orang dapat membuat akun dengan level sebagai Dosen. Adapun proses penambahan akun dosen pada AKEMATIK dapat dilihat pada gambar 2.

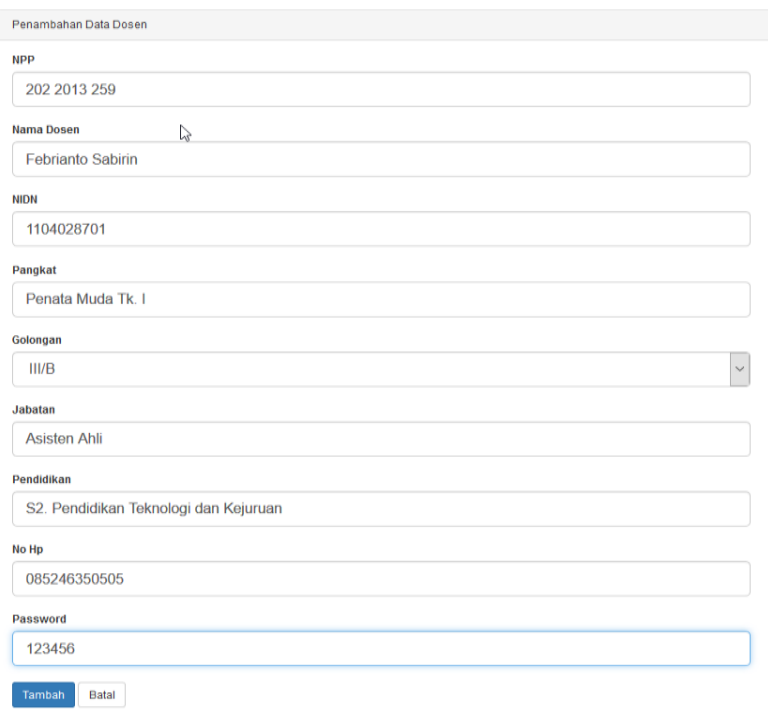

Gambar 2. Penambahan Data Dosen
Setelah mempersiapkan akun untuk dosen, Admin perlu mempersiapkan jadwal perkuliahan untuk masing-masing dosen yang nantinya akan diikuti oleh mahasiswa. Dalam mempersiapkan jadwal perkuliahan Admin perlu mempersiapkan data kurikulum yang berisikan nama kurikulum. Selanjutnya Admin dapat memasukkan data mata kuliah yang berisikan data-data terkait mata kuliah seperti nama, kode, sks, dan semster dari mata kuliah. Terakhir Admin perlu memasukkan data tahun akademik berisikan tahun akademik dan periode akademik. Setelah seluruh data dimasukkan admin dapat membuat jadwal mata kuliah dengan menggabungkan data dari kurikulum, mata kuliah, dan tahun akademik yang akan dihubungkan pada data dosen. Adapun proses pembuatan jadwal kuliah dapat dilihat pada gambar 3.

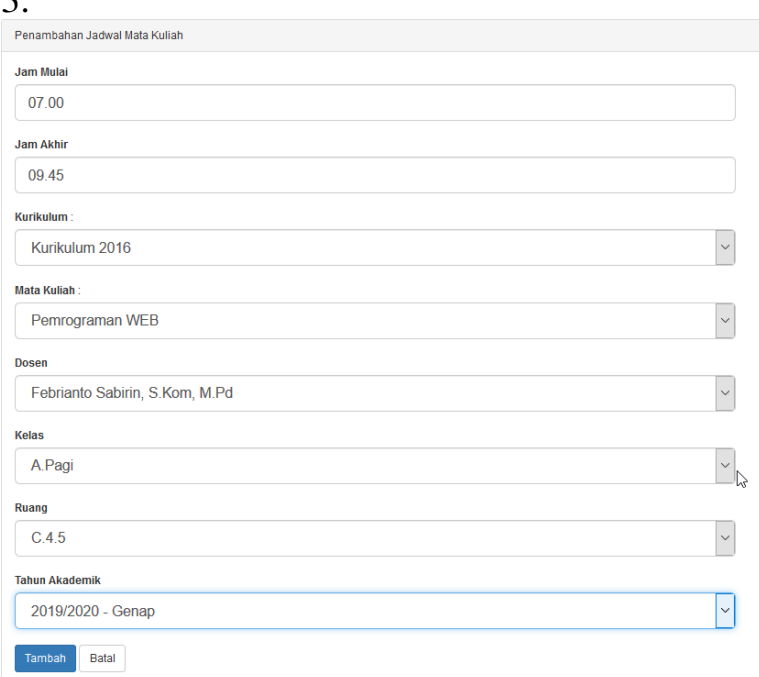

Gambar 3. Penambahan Jadwal Kuliah 
Apabila data jadwal perkuliahan telah disiapkan oleh Admin, maka Mahasiswa dapat mendaftarkan diri pada jadwal yang telah dibuat. Namun sebelum mahasiswa dapat mendaftarkan pada jadwal yang telah disediakan, mahasiswa perlu melakukan registrasi agar dapat terdaftar pada AKEMATIK. Proses registrasi pada AKEMATIK untuk mahasiswa dapat dilihat pada gambar 4, sementara proses mendaftarkan pada jadwal perkuliahan pada gambar 5 .

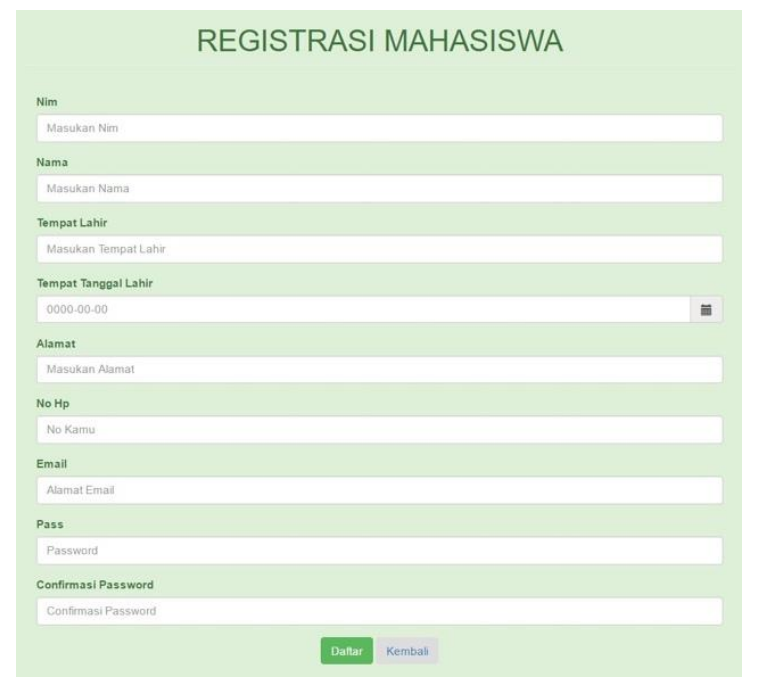

Gambar 4. Registrasi Mahasiswa pada AKEMATIK

Setelah mahasiswa mendaftarkan diri pada AKEMATIK, mahasiswa tidak dapat langsung masuk/login ke dalam AKEMATIK. Mahasiswa perlu menunggu verifikasi akun mahasiswa oleh Admin. Proses verifikasi dilakukan secara manual oleh Admin agar hanya mahasiswa dari Program Studi P.TIK IKIP PGRI Pontianak saja yang dapat diloloskan akunnya.

Apabila akun mahasiswa telah diverifikasi, maka mahasiswa dapat masuk ke dalam AKEMATIK dan kemudian dapat memilih mata kuliah yang akan diikuti. Untuk memudahkan mahasiswa dalam memilih mata kuliah yang akan diikuti diberikan opsi mencari mata kuliah berdasarkan tahun akademik ataupun berdasarkan nama dosen pengampu mata kuliah. Setelah mahasiswa menemukan mata kuliah yang akan diikuti mahasiswa dapat menekan tombol tambah untuk mengajukan permohonan mengikuti mata kuliah yang diinginkan. Namun apabila Mahasiswa salah dalam mengambil mata kuliah, mahasiswa dapat membatalkan dengan menekan tombol keluar. Adapun proses pencarian dan pendaftaran mata kuliah pada AKEMATIK dapat dilihat pada gambar 5 .
2019/2020 - Genap $|v|$ Febrianto Sabirin, S.Kom, M.Pd $\vee$ Search

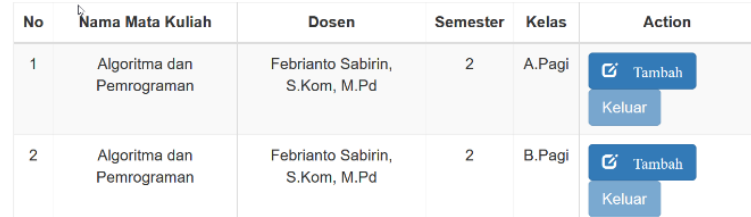

Gambar 5. Mahasiswa Mendaftar pada Jadwal Kuliah pada AKEMATIK

Setelah mahasiswa mendaftarkan diri pada mata kuliah yang dituju, mahasiswa tidak dapat langsung melakukan proses absensi. Akun mahasiswa perlu untuk diverifikasi oleh dosen pengampu mata kuliah, agar mahasiswa dapat melakukan proses absensi. Adapun proses verifikasi mahasiswa dapat dilihat pada gambar 6 .

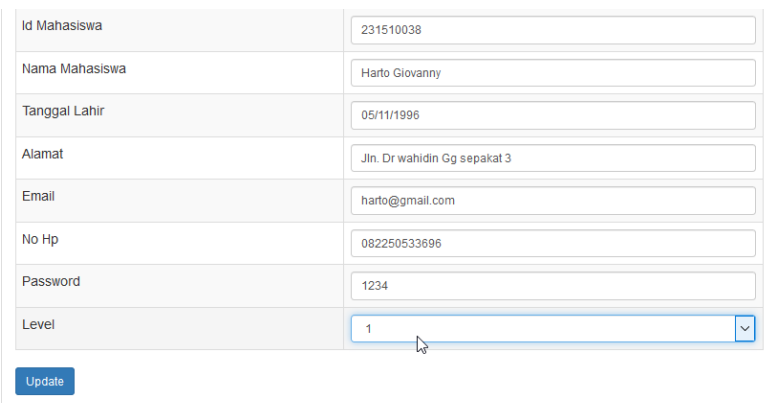

Gambar 6. Proses Verifikasi Mahasiswa oleh Dosen Pengampu Mata Kuliah

Untuk melakukan proses absensi, Dosen perlu membuka kelas terlebih dahulu. Proses membuka kelas sejatinya dilakukan secara bersama-sama dengan mengisi jurnal mengajar, sehingga dosen perlu mengisi data-data terkait jurnal mengajar terlebih dahulu.

AKEMATIK akan secara otomatis menampilkan kelas dengan status terbuka dibagian atas, hal ini bertujuan agar mahasiswa tidak sulit dalam mencari mata kuliah yang sedang dibuka. Mahasiswa hanya perlu memilih jenis kehadiran yaitu Hadir, Izin, Sakit, dan Absen. Apabila mahasiswa tidak melakukan absensi maka secara otomatis, mahasiswa tersebut dianggap tidak hadir dari sistem. Adapun proses absensi mahasiswa dapat dilihat pada gambar 7 . 


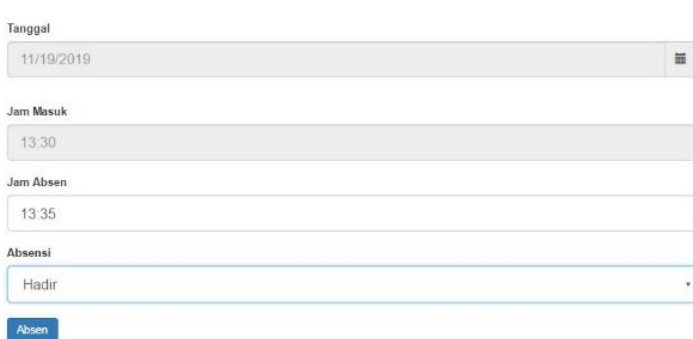

Gambar 7. Kegiatan Absensi oleh Mahasiswa

Apabila mahasiswa telah melakukan absensi, maka dosen dapat melihat pada bagian rekapitulasi absensi. Pada bagian ini dosen dapat melakukan verifikasi terkait kehadiran mahasiswa. Apabila mahasiswa ternyata tidak hadir, tetapi melakukan absensi, dosen dapat mengubah status kehadiran mahasiswa dari hadir menjadi tidak hadir, sakit, atau izin. Apabila seluruh mahasiswa telah diverifikasi maka AKEMATIK secara otomatis akan menutup kelas sehingga mahasiswa tidak dapat melakukan proses absensi. Adapun proses verifikasi kehadiran mahasiswa dapat dilihat pada gambar 8 .

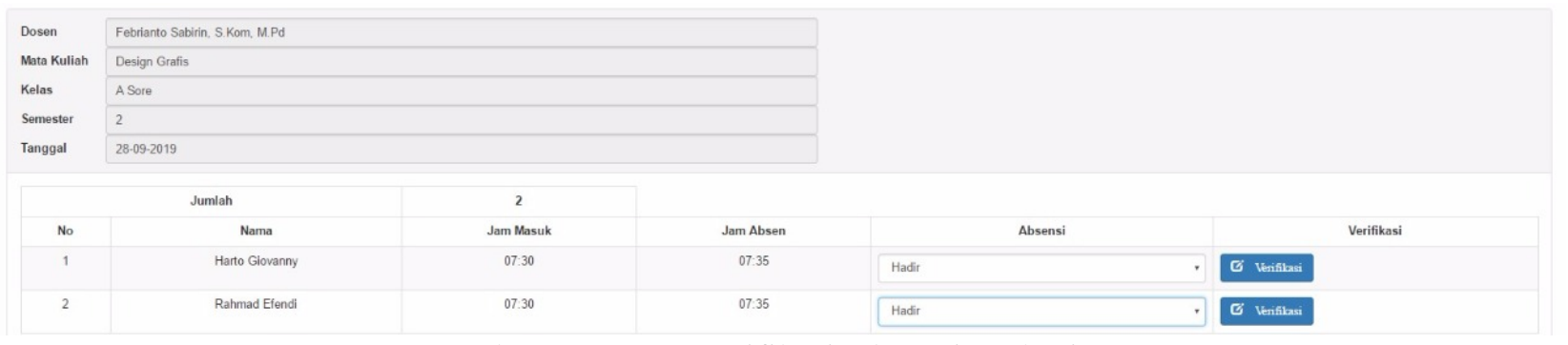

Gambar 8. Proses Verifikasi Absensi Mahasiswa

Setelah proses verifikasi kehadiran dilakukan oleh dosen, dosen dapat melihat hasil rekapitulasi kehadiran mahasiswa. Dosen dapat mencetak hasil rekapitulasi kehadiran siswa tersebut. Hasil rekapitulasi ini secara berkala akan diunggah oleh Admin di halaman
Home AKEMATIK sehingga Pimpinan Program Studi maupun Orang Tua Mahasiswa dapat memantau kehadiran Dosen serta Mahasiswa. Adapun Laporan Jurnal Mengajar dapat dilihat pada Gambar 9.

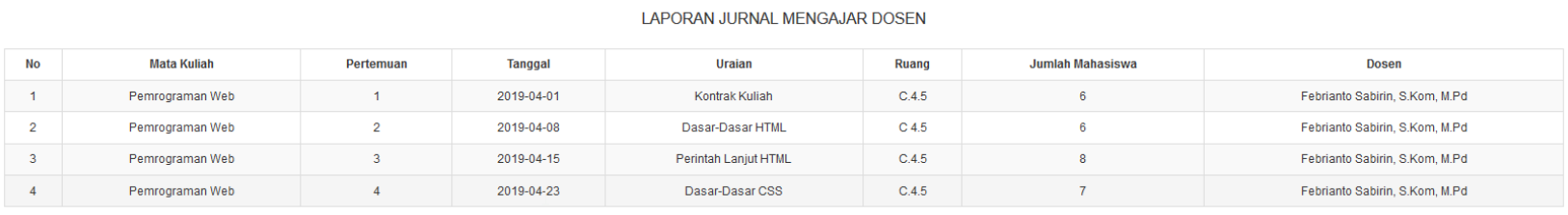

Gambar 9. Laporan Jurnal Mengajar Dosen

Untuk menguji kualitas dari produk yang dikembangkan maka dilakukna pengujian oleh ahli media dan pengguna. Terdapat dua ahli media yang melakukan pengujian terhadap AKEMATIK, dan untuk pengujian terhadap pengguna digunakan 15 dosen dan 30 mahasiswa sebagai sampel penelitian. Pengujian ahli media dilakukan untuk melihat apakah fungsi, tampilan, maupun navigasi yang ada pada AKEMATIK telah berjalan dengan baik atau belum. Sementara pengujian dari pengguna berguna untuk melihat respon terhadap sistem sebelum sistem nantinya diterapkan di Program Studi P.TIK IKIP PGRI Pontianak.

Hasil pengujian ahli menunjukkan bahwa AKEMATIK telah bejalan dengan baik. Hal ini terlihat dari jumlah kategori Baik sebesar 58,69\%. Adapun hasil pengujian ahli dapat dilihat pada tabel 1.

Tabel 1. Sebaran Angket Validasi Ahli

\begin{tabular}{lcc}
\hline \multicolumn{1}{c}{ Kategori } & F & $\mathbf{( \% )}$ \\
\hline Sangat Baik & 16 & 34,78 \\
Baik & 27 & 58,69 \\
Cukup Baik & 3 & 6,52 \\
Kurang Baik & 0 & 0 \\
Sangat Kurang Baik & 0 & 0 \\
\hline \multicolumn{1}{c}{ Jumlah } & 46 & 100 \\
\hline
\end{tabular}

Hasil validasi ahli media dihitung dan analisis untuk mencari nilai rata-rata dan melihat apakah 
sistem informasi yang dikembangkan sudah layak dan memiliki saran-saran perbaikan dalam pengembangan lanjutan. Berdasarkan hasil dari validasi ahli media diatas, diketahui total nilai validasi yaitu 197 dari skor maksimal 230 dengan rata-rata 4,28. Untuk bagian tampilan sudah dapat digolongkan dengan baik, dimana tampilan telah konsisten, mudah dipahami, dan desain sudah tergolong baik. Untuk navigasi, seluruhnya telah berjalan dengan baik atau tidak terjadi kesalahan navigasi sama sekali, dan telah didukung berbagai keterangan pendukung. Untuk bagian fungsi sebagian besar telah berjalan dengan benar, tetapi terdapat beberapa hal yang perlu ditingkatkan seperti proses verifikasi maupun sorting yang belum maksimal.Hasil analisis validasi ahli media yaitu bahwa aplikasi kehadiran mahasiwa P.TIK layak untuk digunakan dan dilakukan uji coba alpha.

Uji coba alpha dilakukan untuk mengetahui tanggapan, saran dan kritik dari 16 dosen dan 30 mahasiswa Program Studi P.TIK terkait AKEMATIK. Diketahui bahwa mayoritas jawaban responden berada pada kategori baik dengan persentase $57,46 \%$. Hasil sebaran jawaban responden dan kategori jawaban dapat disajikan dalam tabel 2 dan grafik pada gambar 9 .

\begin{tabular}{lcc}
\multicolumn{3}{c}{ Tabel 2. Sebaran Angket Uji Coba Alpha } \\
\hline \multicolumn{1}{c}{ Kategori } & F & $\mathbf{( \% )}$ \\
\hline Sangat Baik & 211 & 42,54 \\
Baik & 285 & 57,46 \\
Cukup Baik & 0 & 11,78 \\
Kurang Baik & 8 & 0,89 \\
Sangat Kurang Baik & 0 & 0 \\
\hline \multicolumn{1}{c}{ Jumlah } & 900 & 100 \\
\hline
\end{tabular}

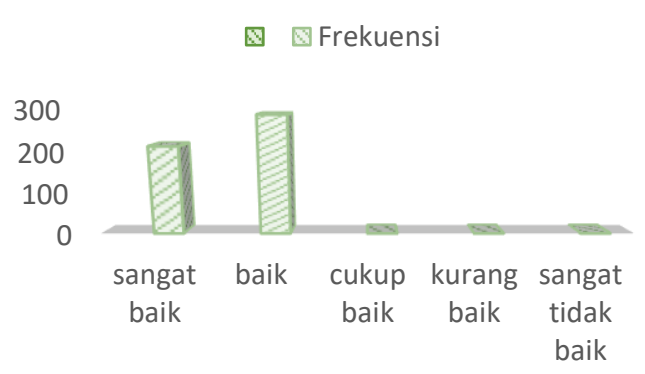

Gambar 9. Grafik Frekuensi Uji Coba Alpha

Hasil uji coba alpha terkait AKEMATIK selanjutnya dihitung dan analisis untuk mencari nilai rata-rata dan melihat apakah aplikasi yang dikembangkan sudah layak untuk diimplementasikan pada kelompok yang lebih besar. Berdasarkan data hasil dari uji coba alpha pada AKEMATIK diperoleh nilai total sebesar 3702 dari skor maksimal 4500 dengan nilai ratarata sebesar 4,113. Hasil analisis uji coba alpha diperoleh hasil bahwa aplikasi layak dan sangat baik untuk digunakan di lingkungan Program Studi P.TIK.

AKEMATIK yang dikembangkan memiliki berbagai keuntungan yaitu untuk mempermudah dosen dalam mengisi jurnal mengajar dosen. Saat dosen membuat jurnal mengajar, mahasiswa dapat melakukan absensi, lalu dosen dapat melakukan verifikasi data kehadiran. Hasil penelitian ini sejalan dengan beberapa penelitian terkait sistem absensi seperti penelitian Paramitha, yang menunjukkan bahwa sistem absensi memberikan kemudahan guru dalam mengolah data kehadiran siswa[15]. Selain itu, menurut penelitian Enggari, pengembangan sistem informasi absensi juga dapat memberikan informasi yang lebih akuntabel baik kepada pimpinan program studi, mahasiswa, dosen atau aktor-aktor lain yang membutuhkan informasi terkait kehadiran[5].

\section{KESIMPULAN}

Pengembangan aplikasi kehadiran mahasiswa dilakukan berdasarkan perancangan yang telah dilakukan dengan menggunakan model ADDIE. Model ADDIE menghasilkan analisis dan perancangan desain yang berupa analisis kebutuhan aplikasi, perancangan alur aplikasi (UML), perancangan database, dan perancangan antarmuka.

Aplikasi yang dikembangkan sudah mengalami tahapan pengujian seperti uji ahli media dan uji alpha. Uji ahli media dilakukan untuk mendapatkan validasi dan saran-saran terkait aplikasi. Berdasarkan uji ahli media diperoleh hasil hasil yaitu rata-rata 4,28 dan berada pada kategori sangat baik. Sedangkan, uji alpha dilakukan kepada 15 dosen dan 30 mahasiswa yang ada di lingkungan program studi P.TIK. Rata-rata hasil uji alpha adalah sebesar 4,113 atau berada pada kategori sangat baik. Oleh karena itu, aplikasi sudah dapat digunakan dalam mendukung kegiatan belajar mengajar di Program Studi P.TIK IKIP PGRI Pontianak. 


\section{DAfTar Pustaka}

[1] Hasugian, P.S. (2018). Perancangan Website Sebagai Media Promosi dan Informasi. Journal of Informatic Pelita Nasantara, 3 (1), 82-86

[2] Madjid, N.W.A., Ridwan, T., Setiadi, B. W., \& Nurdiyanto, H. (2018). A Comparative Analysis: Web Design of Universities in Indonesia and American Countries Based on CNET and Hall Theory. Proceedings of International Conference of Social Science (ICOSS 2018). Diakses dari: https://pdfs.semanticscholar.org/9ede/3fe874f 77ed7e2635c210e1615fa1a235ec7.pdf, tanggal 1 November 2019.

[3] Sulistyarini, D. \& Sabirin, F. (2018). Analisis Perancangan Sistem Informasi Administrasi Program Studi (Siap) Pendidikan Teknologi Informasi Dan Komunikasi. Jurnal Penelitian dan Pengembangan Sosial Humaniora, 2 (1), Hal 22-29.

[4] Satriawan, M. S., Sarwosri, \& Sunaryono, D. (2017). Rancang Bangun Integrasi Aplikasi Sistem Kehadiran Mahasiswa Menggunakan Kerangka Kerja Laravel Studi Kasus Jurusan Teknik Informatika ITS. Jurnal Teknik ITS, 6 (2), A704-A706.

[5] Enggari, S. dan Darman. (2016). Perancangan Sistem Informasi Absensi Siswa MTsN Pariaman Selatan dengan Menggunakan PHP MySQL dan SMS GateWay. Jurnal Teknologi, 6 (1). 27-34.

[6] Irawan, A. dan Noor, T. (2014). Sistem Informasi Absensi Mahasiswa (Studi Kasus Jurusan Administrasi Bisnis POLIBAN). Jurnal INTEKNA, XIV (2). 102-109.

[7] Andini, Anastassa F., Irzal, Med., \& Arafiyah, Ria. (2017). Perancangan dan Implementasi SIstem Absensi Online Berbasis Android di Lingkungan Universitas Negeri Jakarta. Jurnal Ilmu Komputer dan Aplikasi, 1 (1), 1-10.

[8] Kemenristekdikti. (2015). Peraturan Mentri Riset, Teknologi, dan Pendidikan Tinggi Nomor 44 Tentang Standar Nasional Pendidikan Tinggi.

[9] Amelia \& Susi. (2014). Pengaruh Kehadiran Perkuliahan Terhadap Nilai Akhir Mahasiswa Menggunakan Metode Fuzzy Quantificatioon Theory 1. Jurnal Sains dan Teknologi Informasi, 3 (1).
[10] A. Leitch, Robert \& K. Davis, Roscoe. (1983). Accounting Information System. New Jersey : Prentice-Hall.

[11]Alter, S. (2013). Work System Theory: Overview of Core Concepts, Extensions, and Challenges for the Future Work. Journal of the Association for Information Systems, 14 (2), $72-121$.

[12] Symons, V.J. (1991). Impacts of Information Systems: Four Perspectives. Information and Software Technology, 33 (3), 181-190.

[13] Boel, S.K., \& Kecmanovic, D.C. (2015). What is an Information System?. 48 ${ }^{\text {th }}$ Hawaii International Conference on System Sciences, 4959-4968.

[14] Wellens, P. (2015). Practical Web Development. Packt Publishing.

[15]Connolly, R., \& Hoar, R. (2015). Fundamentals of Web Development. Person Education.

[16] Paramitha, C, P., Risnasari, M., dan Saputro, S.D. (2018). Pengembangan Sistem Infromasi Absensi Siswa Berbasis Java Desktop di SMA Darul Kholil Bangkalan. Jurnal Ilmiah Edutic. 4 (2), 63-70

\section{Biodata Penulis}

Ferry Marlianto, lahir di Pontianak, 16 Maret 1982. Meraih gelar Sarjana Komputer bidang Ilmu Komputer di Institut Sains dan Teknologi AKPRIND Yogyakarta pada tahun 2008 dan meraih gelar Magister Pendidikan pada bidang Pendidikan Matematika dan Ilmu Pengetahuan Alam di Universitas Sebelas Maret Surakarta pada tahun 2011. Bekerja sebagai dosen di Program Studi Pendidikan Teknologi Informasi dan Komputer di IKIP PGRI Pontianak sejak tahun 2009. Fokus penelitian pada pengembangan model pembelajaran dan sistem informasi pendidikan.

Dewi Sulistiyarini, lahir di Pontianak, 13 Desember 1989. Meraih gelar Sarjana Komputer bidang Teknik Informatika di Unviversitas Islam Indonesia pada Tahun 2011 dan meraih gelar Magister Pendidikan pada bidang Pendidikan Teknologi dan Kejuruan konsentrasi Pendidikan Teknik Informatika di Universitas Negeri Yogyakarta pada tahun 2014. Bekerja sebagai dosen di Program Studi Pendidikan Teknologi Informasi dan Komputer di IKIP PGRI Pontianak sejak tahun 2011. Fokus penelitian pada literasi 
abad 21, soft skills, dan sistem informasi pendidikan.

Febrianto Sabirin, lahir di Pontianak, 4 Februari 1987. Meraih gelar Sarjana Komputer bidang Teknik Informatika di STMIK Pontianak pada Tahun 2010 dan meraih gelar Magister Pendidikan pada bidang Pendidikan Teknologi dan Kejuruan, konsentrasi Pendidikan Teknik Informatika di Universitas Negeri Yogyakarta pada Tahun 2015. Bekerja sebagai dosen di Program Studi Pendidikan Teknologi Informasi dan Komputer di IKIP PGRI Pontianak sejak tahun 2012. Fokus penelitian pada pembelajaran berbasis proyek, literasi abad 21, soft skill, dan sistem informasi pendidikan. 
